\title{
MARKETING IN THE NON-PROFIT SPHERE ON THE EXAMPLE OF THE INTERNATIONAL STUDENT ORGANIZATION "BEST" OF THE URAL FEDERAL UNIVERSITY
}

\author{
Evgeniya Yazovskikh ${ }^{1}$ \\ Oksana Yatsenko
}

DOI: https://doi.org/10.31410/ERAZ.2019.153

\begin{abstract}
Every year, more and more non-profit organizations are being created in our country and in the world, the main purpose of which is not related to making a profit and distributing it among its members. The main goal of non-profit organizations activities is to obtain a social effect, solve the problems of certain groups of people, improve the quality of life of the region and the society. The social effect, the carrier of which is considered a non-commercial product and which arises as a result of non-commercial exchange, appears due to the satisfaction of consumer demand. It should serve as a signal to investors about the need to finance the activities of a non-commercial entity. The social effect is an indicator characterizing the qualitative aspect of the change that has already occurred (raising the educational level of the population, satisfaction with social status or a financial situation, increasing the number of children in families). One of the best examples of non-profit organizations is "BEST" (Board of European Students of Technology). It is a non-political volunteer organization aimed at developing engineering students. It helps students from Europe be internationally minded, better understand the culture of different countries and develop the potential for working at the international level. Nowadays there are ninety-six local BEST groups in thirty-three countries, four of which are located in Russia: two in Yekaterinburg, and one in Moscow and one in St. Petersburg. In the capital of the Urals, one of the groups exists on the basis of the Ural Federal University named after the first President of Russia B.N.Yeltsin.
\end{abstract}

Keywords: marketing, marketing mix, non-profit organizations, social effect, international student organizations.

\section{INTRODUCTION}

$\mathrm{N}^{\circ}$ owadays the number of non-profit organizations is growing. The competition is getting higher. Each organization is trying to attract more consumers. The specifics of promoting non-profit organizations differs from the marketing activity of commercial organizations.

At the same time, one can observe the penetration of marketing elements into the non-commercial sphere. Marketing tools are widely used in various non-commercial activity: political parties, charitable foundations, state budget structures, etc.

The federal law states that "non-profit organizations can be created to achieve social, charitable, scientific and managerial goals, in order to protect the health of citizens, develop physical culture and sports, meet the spiritual and other needs of citizens, protect the rights, legitimate interests of citizens and organizations, and resolve disputes and conflicts, the provision of legal assistance, as well as for other purposes aimed at achieving public goods.” [1]

\footnotetext{
1 Ural Federal University named after the first President of Russia B.N.Yeltsin, 620002, 19 Mira street, Ekaterinburg, Russia

2 Ural Federal University named after the first President of Russia B.N.Yeltsin, 620002, 19 Mira street, Ekaterinburg, Russia
} 
These organizations do not receive profits, their work is entirely carried out on enthusiasm of their creators and participants. The goals of non-profit organizations and the people who are in them are different. People joining such organizations seek to satisfy both personal interests and influence the life of society. The main idea of non-profit organizations is to have a positive impact on society and benefit. Measuring the social effect is carried out by various approaches, namely market, income and cost.

Thus, non-profit organizations can be characterized as socially useful associations whose activities are aimed at improving the state of society. Annually the number of such organizations increases, as people strive to improve the life quality of the population, focusing on intangible benefits, such as spiritual, educational and other values.

\section{METHODOLOGY}

$\mathrm{Ph}$. Kotler gives the following definition: "non-commercial marketing or marketing of non-commercial organizations is marketing carried out by organizations and individuals who act in the public interests or advocate any idea and do not try to make a profit." [2, p.364]

A. Braverman argues that "non-profit organizations do not set goals for increasing profits; for them non-financial goals are as important as financial goals." [3, p.58].

As for making profits by non-profit organizations, in accordance with the law of the Russian Federation, "a non-profit organization can carry out entrepreneurial and other income-generating activities only in case it serves the achievement of the goals for which it was created and corresponds to the specified goals, provided that such an activity is specified in its constituent documents." [4]

Thus, non-profit organizations in the Russian Federation have the right to carry out activities aimed at making a profit for their further functioning, however the members of such communities have no right to extract personal financial gain for themselves.

\section{DISCUSSION AND RESULTS}

In non-profit organizations fundraising plays an important role, i.e. the activity of the non-profit organization based on its unique mission and strategy, using effective and productive ways to get the resources it needs to implement its programs and achieve its goals, providing the desired satisfaction to the donor.

$\mathrm{Ph}$. Kotler identifies 4 types of non-commercial marketing: marketing of ideas, marketing of individuals, marketing of places and marketing of services [5, p. 578]. The task of the latter is to promote services to increase its value, attract more consumers, form a circle of loyal customers, etc. $[6$, p. 356].

In order to carry out marketing activities, non-profit organizations must perform traditional marketing functions. In the activities of non-profit organizations, an important role is played by the marketing mix.

The initial concept was created by D. McCarthy in 1981, it includes four components ("4Ps"): product, price, distribution channels (place), communication (promotion). In the future, this 
concept was expanded M. Bitner. Other 3 Ps were added: people, process, material evidence (physical evidence) [7, p. 56].

Promotional complex tools are widely used in the marketing activities of non-profit organizations, but each component of the marketing mix in non-profit organizations manifests itself in a different way compared to commercial organizations.

"BEST" (Board of European Students of Technology) is a non-profit, non-political volunteer organization aimed at developing engineering students. The idea of creating this organization appeared in 1987 in Stockholm during the conference dedicated to students of engineering specialties.

Following the conference, it was decided to arrange an international week every six months in different countries for European students of engineering specialties to communicate and share experience. After several meetings, "BEST" was organized in 1989 in Berlin. In November 1990, "BEST" organized the first two-week educational courses in Budapest.

The organization began to grow and its local groups (branches) started appearing in different European countries. Since 2002, "BEST" has been organizing EBEC engineering competitions on a local, regional and global level.

The organization has three stakeholders: students (yellow color on the logo), university (green color on the logo) and company (blue color on the logo). If a local group does not have support for one of these components, then it cannot exist. To support organization's activities, partners are often required, such as Coca-Cola, Sberbank, UMMC, Unilever, ZIC and others.

The vision of "BEST" is power in diversity. It means that people understand and respect different nationalities and cultures, which makes them more united, responsible and tolerant.

The mission of "BEST" is the development of students. The company allows students to expand their international thinking, learn about the culture of various countries and develop the ability to work in the multicultural environment, creating students' personal growth and revealing their potential.

The international student organization "BEST" has 5 values: flexibility, friendship, fun, improvement and learning. Let's consider them in details.

1. Flexibility. Members of the organization look for the opportunity to make changes and cope with unstable situations around. They are always open to something new, value and increase their mobility, and also quickly react to changing situations and obstacles they face.

2. Friendship. In "BEST" people build good relationships in which they help, support and care for each other. Teamwork is valuable to them. They focus on each person who participates in their activities and thus create synergy.

3. Members of the organization enjoy all that they do. They appreciate the positive emotions of people and strive to ensure that everyone is pleased to work in the organization. They are eager to get involved in their work and try to convey this feeling to others.

4. Improvement. They constantly strive to raise the standards of everything they do. They also use all their creativity, imagination and potential to improve their work. This ensures the continued organization development and the people in it. 
5. Training. People in the organization acquire new skills and knowledge through experience. They value this experience and strive to get it from all areas of their work. They also value personal development and strive for open learning community where everyone can freely share their ideas.

As for local groups, their main activities are organizing and promoting international external and domestic events, as well as local ones. The latter, as a rule, are aimed at the students of their University, e.g., some local groups organize job fairs or company presentations at their Universities. Since almost all "BEST" events are completely free of charge, local "BEST" groups need fundraising these projects.

The local group "BEST" has existed in Ural federal University since April 14, 2003. Every person coming to the organization can find something for his personal development and choose the sphere in which he wants to learn and improve.

The international student organization "BEST" is engaged in developing students, both within its structure and not belonging to its number. They learn to communicate, build relationships with large companies for cooperation, promote materials, manage and coordinate many other important and useful things. The organization allows students to travel to different countries, where they can find new friends, practice the language and find a good job abroad. All this attracts many students throughout Europe. Inside the organization, a friendly atmosphere reigns, there is mutual assistance and mutual support.

Based on the analysis of the marketing activities of the "BEST" organization (SWOT - the analysis of an international student organization, competitiveness analysis, segmentation of consumers of student non-profit organizations), the following marketing decisions were made: strategic, tactical and operational.

Based on the SWOT analysis of the international student organization "BEST" of Ural federal University, the weaknesses of this non-profit organization were identified:

- lack of consistency in providing information on the work being done (e.g., in core team, in departments, etc.) to other members of the organization;

- insufficient level of qualifications of organization members in working activities, in managing the organization, etc.;

- insufficiently effective work of PR department;

- a low English level of many "BEST" Ekaterinburg UrFU members;

- a lack of mechanisms for motivating non-profit organization staff.

The greatest strengths of the international student organization "BEST" are successful communications with stakeholders (University support, companies that are ready to cooperate with the international student organization "BEST", high demand for student services).

In the presence of such serious threats to the external environment as the absence of sponsors willing to support the international student organization "BEST" and the availability of such services among competing organizations, it is important for the non-profit organization "BEST" to improve their competitiveness promotion of the "BEST" brand, increase the service promotion complex, develop a participant motivation system and work out the conditions for learning 
English by all the organization members, relying on the strengths of the non-profit organization and using the capabilities of the external environment.

Based on the segmentation, the target segments were identified and the basic values of consumers were fixed, which must be oriented to improve the efficiency of the service delivery process. They are the following: unique educational activities; technical focus of activities; fame of the organization; the opportunity to get acquainted with the culture of Europe and Russia.

In addition to consumer analysis, a competitor analysis was conducted based on a competitiveness polygon and a competitiveness assessment sheet. The international student organization "BEST" has two closest competitors in the market of non-commercial services in the city of Yekaterinburg: the international student organization "AISEC" and the student organization "Buddysystem".

AIESEC is an international youth public organization that brings together students and recent University graduates to uncover and develop the leadership and professional potential of young people to make a positive contribution to society.

The support service of foreign students in UrFU is «Buddysystem» organization. The main purpose of the service is meeting and accompanying foreign students, assisting in their adaptation at the University and in extracurricular life, as well as promoting the development of intercultural competencies among students of Ural federal University named after the first President of Russia B.N. Yeltsin.

\section{CONCLUSION}

Having analyzed the activities of the international student organization "BEST" in accordance with the matrix of I. Ansoff, one can conclude that the most appropriate strategy for the organization is the penetration strategy. In order to implement a strategic marketing solution, a great variety of activities was developed:

- personnel training in CRM, as well as training for staff development;

- developing activities with greater focus on Russian stakeholders using the URFU brand, as well as creating an advertising campaign to attract Russian stakeholders;

- conducting online conferences and events (e.g., training) with foreign students and members of European local "BEST" groups;

- holding joint events for consumers of international student organizations and students and creating a joint advertising campaign;

- developing a financial contingency plan, and an advance miscalculation of opportunities for saving, avoiding risks and finding alternative sources of funding in case of sponsors lack;

- developing larger scale activities, taking into account government support;

- organizing joint activities for members of the organization in English to increase employee motivation, production with the symbols of organizations and events;

- participating in events organized by state structures on the basis of cooperation with them as partners;

- developing an advertising campaign to attract more consumers than its competitors;

- developing larger scale activities, taking into account possibilities of state support; 
- organizing joint activities for members of the organization in English to increase employee motivation, production with the symbols of organizations and events;

- organizing internships with the provision of a workplace in the company in the future to the best students, including members of the international student organization "BEST";

- conducting an educational course with the participation of external media for the purpose of PR;

- staff development with using opportunities and training programs of state support;

- conducting events to increase the motivation of employees of the corporate relations department;

- systemic publication of articles on non-profit organization activities in a youth magazine, organizing TV filming events held at the UrFU site, making a film about a local BEST group together with the media;

- inviting company representatives as speakers for events with feedback;

- introducing new communication channels into the system of interacting the international student organization "BEST" with state structures implementing a program of support for volunteer organizations;

- holding an event based on public readings of image articles of other local "BEST" groups;

- conducting a survey among potential participants to select the most interesting topic of an educational event;

- conducting a competition in the mailing list for writing an image article of the organization and its further publication in external media sources;

- organizing and its further publishing in external media sources;

- advertising for companies providing career opportunities in Gmail and other online services;

- creating a special mailing list for consumers of services, holding information meetings in the mode of online conferences with the aim of improving the quality of organized events.

The implementation of these measures will allow "BEST" to further improve its competitiveness, provide an opportunity to continue receiving a social effect, to function successfully as a non-profit organization.

\section{REFERENCES}

[1] Federal law of 12.01.1996 N 7-FL (as amended on November 14, 2017) "On non-profit organizations" (as amended on January 1, 2018).

[2] Kotler Ph. Marketing Management, Peter, Saint Petersburg, 2005.

[3] Braverman A. Marketing in Russian economy of the transition period: methodology and practice, Economics, Moscow, 2015.

[4] Civil Code of the Russian Federation (Part One) of 11/30/1994 N 51-FL (as amended on December 29, 2017).

[5] Kotler Ph. Marketing, Peter, Saint Petersburg, 2015.

[6] Kotler F. A short course of Marketing, Williams Publishing House, Moscow, 2007.

[7] Bitner M. The impact of Physical surrounding on customer and employees, Journal of Marketing, № 4, 1992. 